\title{
A PROTEÇÃO SOCIAL AO IDOSO E O TRABALHO DE INCLUSÃO: UMA REVISÃO INTEGRATIVA DA LITERATURA
}

\section{REVISÃO INTEGRATIVA}

LEITE, Michael Douglas Sousa ${ }^{1}$

MOURA, Wanessa Arnaud ${ }^{2}$

FRANÇA, Laerte Ferreira de Morais ${ }^{3}$

LAVOR, Leudiane Holanda 4

CAVALCANTE, Matheus Lôbo ${ }^{5}$

SARMENTO, Thaise de Abreu Brasileiro ${ }^{6}$

${ }^{1}$ Mestrando em Sistemas Agroindústrias - UFCG, Pós-Graduado em Docência do Ensino Superior, Graduado em Administração - UFCG.

${ }^{2}$ Mestranda em Sistemas Agroindústrias - UFCG, Pós-Graduada em Fisioterapia Traumato-ortopédica e Desportiva, Graduada em Fisioterapia (FIP).

3 Mestrando em Sistemas Agroindústrias - UFCG, Pós-Graduado em Direito Administrativo pela Universidade Gama Filho, Bacharel em Ciências Jurídicas e Sociais - UFCG e Graduado em Geografia - UFCG.

${ }^{4}$ Mestranda em Sistemas Agroindústrias - UFCG, Pós-Graduada em Gestão Social (FAMETRO), Graduada em Pedagogia (UECE).

5 Mestrando em Sistemas Agroindústrias - UFCG, Pós-Graduado em Direito Administrativo e Gestão Pública (Urca); Especialista em Língua Portuguesa e Literatura, Bacharel em Direito (Urca/Campus Iguatu).

${ }^{6}$ Mestranda em Sistemas Agroindústrias - UFCG, Residência em pediatria pelo Hospital Universitário Osvaldo Cruz/UPE, e Graduada em Medicina pela Faculdade de Medicina Nova Esperança - FAMENE. 
SILVA, Ana Maria ${ }^{7}$

LEITE, Michael Douglas Sousa. Et al. A proteção social ao idoso e o trabalho de inclusão: Uma revisão integrativa da literatura. Revista Científica Multidisciplinar Núcleo do Conhecimento. Ano 06, Ed. 01, Vol. 04, pp. 92-112. Janeiro de 2021. ISSN: 2448-0959, Link de acesso: https://www.nucleodoconhecimento.com.br/cienciassociais/trabalho-de-inclusao

\section{RESUMO}

Apesar das conquistas evidenciadas nas últimas décadas existe ainda preconceitos que envolvem o envelhecimento no meio social, faltando assim valorizar e respeitar os idosos. Pensando nisso, o presente estudo investigou na literatura acadêmica temáticas que contemplam questões relacionadas aos idosos e os desafios da sociedade atual para a devida proteção, integração e inclusão social nas políticas públicas. Para tanto, a pesquisa trata-se de um estudo do tipo revisão integrativa da literatura. Para levantamento dos artigos foram utilizadas as seguintes bases: Literatura Latino-americana e do Caribe em Ciências da Saúde (LILACS), Biblioteca Científica Eletrônica em Linha (SCIELO) e PubMed Central (PMC) e os descritores "Proteção Social" "Idoso" e "Inclusão". Os resultados do estudo apontam a necessidade de garantir direitos fundamentais, ou seja, melhores condições de saúde, educação, alimentação, lazer, trabalho, cultura, e liberdade, sobretudo a dignidade. Outra questão apresentada é que a instituição do Estatuto do Idoso representa um avanço significativo na legislação, com o escopo de garantir o respeito aos idosos, como também a consolidação e ampliação dos seus direitos, com o propósito de ofertar-Ihes cidadania de fato e de direito às pessoas com idade superior a 60 anos. Partindo dos objetivos estabelecidos para este estudo, concluiu-se que os grupos de convivência espalhados pelo Brasil, são ações que buscam o desenvolvimento social, psicológico e biológico dos idosos, esses participantes, visualizam o grupo como um

${ }^{7}$ Especialista em Psicopedagogia (FIP), Licenciada em Ensino Fundamental de $1^{\circ} \mathrm{a}$ $8^{\circ}$ Série, nas Áreas específicas (2003/UECE) e Bacharel em Serviço Social (UNITINS). 
ambiente de encontros para partilhar o lazer, assuntos importantes da vida e expressar-se. Desse modo, é um local propício para a resolução de problemas de ordem social e biológica, através da formação de uma rede de solidariedade.

Palavras-Chave: Direito, idoso, inclusão, Políticas Públicas, Proteção Social.

\section{INTRODUÇÃO}

Os estudos sobre idosos vêm ganhando maior notoriedade e sistematização a partir da década de 1990 e tendem a aumentar, visto a visibilidade social. Além disso, a queda expressiva dos níveis de fecundidade e da mortalidade no Brasil produziu transformações significativas no padrão etário da população ao longo dos anos, o que aponta para uma representação demográfica mais envelhecida (PESSÔA, 2010; BARROSO et al., 2015; DENTZ; SILVA, 2017).

Segundo Silva e Yazbek (2014) estima-se que em 2025, os idosos no Brasil atingirão uma população de 30 milhões de pessoas, sendo equivalente a quase (15\%), assim o envelhecimento da população é irreversível. Evidenciando melhor a dimensão do acelerado processo de envelhecimento no país, coloca-se como parâmetro, a França, onde foram necessários quase 120 anos para que o número de idosos passasse de mais $(7 \%)$ do total dos habitantes do país para $(14 \%)$. Destarte, o Brasil vai experimentar um aumento equivalente num período de 20 anos.

Rosa (2012) e Barroso et al., (2015) destacam que o envelhecimento é uma fase única da existência, marcada por modificações bioquímicas, morfológicas, psicológicas e fisiológicas específicas e profundamente ligadas à ocorrência do tempo, trata-se de um ciclo ao ser humano inerente, que carece de atenção tanto da família, quanto das autoridades políticas competentes no curso de direcionar políticas públicas à figura idosa, sobretudo nas áreas do direito, saúde, assistência e previdência.

Assim envelhecer, necessariamente, não denota adoecer, pois, um sujeito pode envelhecer naturalmente e conviver bem com limitações que a idade the impõe. Entretanto, os estigmas negativos e as representações sociais giram em torno da 
doença e da dependência, apontando para a normalidade destes aspectos, além de os considerarem inevitáveis. Ou seja, grande parte da população considera que o declínio biológico direciona esta fase à presença de doenças (principalmente crônicodegenerativas) e dificuldades funcionais que avançam com a idade (SILVA; YAZBEK, 2014).

Por outro lado, vivemos numa sociedade que cultua o moderno, a novidade, a juventude, onde os idosos são visualizados como caretas, ultrapassados ou até mesmo, arcaicos. Apesar das conquistas evidências nas últimas décadas - Estatuto do idoso (2003), não podemos descartar que há um aumento crescente da violência e maus tratos à pessoa idosa, tanto no âmbito doméstico/familiar, quanto na esfera institucional e pelo próprio Estado, que age de forma omissa aos direitos legais e reais, uma vez que falha na fomentação de políticas e programas públicos, além de proporcionar ações fragmentadas que em quase nada atendem as necessidades dos idosos (PESSÔA, 2010; BARROSO et al., 2015).

Os preconceitos envoltos no envelhecimento estão no meio social quase sempre, faltando assim a valorização e o respeito aos idosos. O banimento de reflexões alusivas ao envelhecimento não se restringe ao senso comum social que, ao recear as primeiras rugas, pode recusar o tema, mas se encontra inserido no próprio campo acadêmico, que pode valorizar de maneira intensa estudos de segmentos econômico e socialmente ativos em necessidade de intervenções e de melhorias das políticas de atendimento ao idoso.

No Brasil, segundo a Lei 8.842 de 1994 e 10.741 de 2003 considera-se a pessoa idosa com 60 anos ou mais, seguindo-se os padrões estabelecidos pela Organização Mundial de Saúde - OMS. Apesar de predominar muitas vezes o preconceito e discriminação contra esse grupo, vem aumentando a visão de que os idosos podem dar contribuição fundamental na construção de uma sociedade mais humana (KEINERT; ROSA, 2009).

No Brasil é reconhecido no ordenamento jurídico o valor do idoso, apesar da mentalidade utilitarista da sociedade que os marginaliza. Esse reconhecimento é 
devido, a priori, porque são seres humanos por isso, dignos de respeito; posteriormente, em função das suas necessidades decorrentes da idade; e por fim, porque são pessoas que contribuíram, e ainda podem contribuir, para a construção de uma sociedade solidária e justa (KEINERT; ROSA, 2009).

A partir disso, é necessário difundir a todos, inclusive aos próprios idosos, os direitos e garantias a eles conferidos para que possam exigir então, seu cumprimento usando todos os caminhos possíveis. Essas atitudes, nada mais são do que ações para que se respeite a vida em toda a sua plenitude, desde a infância até a velhice, pois o direito à vida só é de fato efetivado se existir dignidade (KEINERT; ROSA, 2009).

Neste sentido, o presente trabalho objetivou identificar na literatura acadêmica (artigos; revistas científicas; anais eletrônicos) temáticas que contemple questões relacionadas aos idosos e os desafios da sociedade atual para a devida proteção, integração e inclusão social nas políticas públicas. Além disso, buscou-se como objetivo específico fazer uma análise sobre o Estatuto do idoso e outros mecanismos de regulamentação dos direitos dos idosos no Brasil; mostrar o papel do centro de convivência do idoso e o desafio da inclusão social.

Vale ressaltar que uma das preocupações das políticas públicas é assegurar os direitos da pessoa idosa, garantindo a acessibilidade da pessoa que envelhece e incentivando sua participação nas relações sociais, evitando o isolamento e exclusão. O grande desafio para perante a população que envelhece está na garantia a esses direitos, com igualdade, pois estando inserido numa sociedade capitalista, desigual, considerado pela sociedade como um "peso", ao invés de serem vistos como pessoa e ser social.

\section{METODOLOGIA}

A presente pesquisa trata-se de um estudo do tipo revisão integrativa da literatura. $\mathrm{O}$ termo "integrativa" se refere à integração de opiniões, conceitos ou ideias. O método da revisão integrativa é utilizado quando se deseja sistematizar o conhecimento científico e traçar um panorama sobre a produção científica que existe com relação à 
temática questionada, permitindo assim, o pesquisador estar próximo da problemática do qual deseja apreciar (WHITEMORE, 2005; BOTELHO, 2011).

Para Mendes (2008) a sua elaboração compreende-se em seis etapas: 1) a escolha da questão para revisão; 2) o estabelecimento de critérios para seleção da amostra; 3) a descrição das características da pesquisa original; 4) a análise dos dados obtidos; 5) a interpretação dos resultados; 6) e a apresentação da revisão.

Diante disso, a realização do estudo busca responder os seguintes questionamentos: de que forma ocorre a proteção social ao idoso? Quais são as medidas de proteção Social baseadas no estatuto do idoso? Como é dado o atendimento nos Centros de Convivência no Brasil?

Para levantamento dos artigos foram utilizadas as seguintes bases: Literatura Latinoamericana e do Caribe em Ciências da Saúde (LILACS), Biblioteca Científica Eletrônica em Linha (SCIELO) e PubMed Central (PMC) e os descritores "Proteção Social" "Idoso" e "Inclusão". De início, a busca pelos descritores foi dada de maneira individual, sendo usado posteriormente o cruzamento segundo o operador booleano "and". Neste sentido, para a seleção da amostra, foram considerados os seguintes critérios de inclusão: artigos publicados no idioma inglês, português e espanhol, no período de 2007 a 2019, que retratam a temática em estudo. Sendo assim, foram excluídos os resumos, livros, teses e dissertações. A tabela 1 mostra a estrutura utilizada na metodologia.

Tabela 1. Publicações encontradas entre os anos de 2007 a 2019 nas bases de dados.

\begin{tabular}{|l|l|l|l|}
\hline DESCRITORES & \multicolumn{3}{l|}{ BASE DE DADOS } \\
\cline { 2 - 4 } & LILACS & SCIELO & PUBMED \\
\hline Proteção Social & 1.390 & 1.516 & 44.872 \\
\hline Idoso & 1350 & 957 & 1291 \\
\hline Inclusão & 694 & 327 & 356 \\
\hline Proteção Social and Idoso & 46 & 81 & 72 \\
\hline Proteção Social and Inclusão & 48 & 75 & 50 \\
\hline
\end{tabular}




\begin{tabular}{|l|l|l|l|}
\hline Inclusão and Idoso & 24 & 73 & 53 \\
\hline Proteção Social and Idoso and Inclusão & 14 & 2 & 7 \\
\hline Artigos Escolhidos & $\mathbf{3}$ & $\mathbf{6}$ & $\mathbf{3}$ \\
\hline
\end{tabular}

Fonte: Dados da Pesquisa, 2019.

Sobre o processo de busca dos artigos, verificou-se a obediência às especificidades de todas as bases de dados utilizadas e a seleção destes, de modo a satisfazer os seguintes critérios: seguimento da temática do estudo, sendo capaz de responder à questão norteadora da pesquisa descrita no idioma português, espanhol ou inglês, além de estar enquadrado no período de 2007 a 2019, e permitir a acessibilidade ao seu conteúdo completo.

A realização do levantamento das biografias ocorreu nos meses de junho e julho de 2019. Diante dos requisitos mencionados acima e excluindo-se os artigos nas bases repetitivos, foram selecionados doze artigos.

Por último, os resultados foram agrupados por categorias temáticas.

\section{RESULTADOS}

O estudo contemplou a síntese do estudo de doze artigos, dos quais estão expostos na tabela 2.

Tabela 2. Apresentação das principais características dos artigos

\begin{tabular}{|l|l|l|l|}
\hline Título & Autor(es) & $\begin{array}{l}\text { Ano/ } \\
\text { País }\end{array}$ & Desfechos \\
\hline $\begin{array}{l}\text { Política nacional de } \\
\text { atenção ao idoso e a } \\
\text { contribuição da } \\
\text { enfermagem }\end{array}$ & R. A. P.; et al., & Brasil & $\begin{array}{l}\text { Os atores sociais envolvidos na } \\
\text { Paca Nacional de Atenção ao }\end{array}$ \\
& & & $\begin{array}{l}\text { Idoso foram os idosos, as } \\
\text { famílias, a comunidade e a } \\
\text { equipe de saúde. A política tem } \\
\text { proporcionado, aos atores sociais }\end{array}$ \\
\hline
\end{tabular}




\begin{tabular}{|c|c|c|c|}
\hline & & & $\begin{array}{l}\text { envolvidos, conscientização para } \\
\text { justiça social e garantia plena dos } \\
\text { direitos aos idosos, na Política } \\
\text { Nacional de Atenção ao Idoso } \\
\text { envolve o processo de cuidar no } \\
\text { ciclo de vida e nos vários níveis } \\
\text { de atenção à saúde, onde se } \\
\text { inclui a saúde do idoso, assim } \\
\text { como a participação na } \\
\text { elaboração e implementação } \\
\text { dessa política. }\end{array}$ \\
\hline $\begin{array}{l}\text { Fórum } \\
\text { Envelhecimento } \\
\text { populacional e as } \\
\text { informações de } \\
\text { saúde do PNAD: } \\
\text { demandas e desafios } \\
\text { contemporâneos }\end{array}$ & VERAS, R. & $\begin{array}{l}2007 / \\
\text { Brasil }\end{array}$ & $\begin{array}{l}\text { Contribuição de autores para o } \\
\text { fórum de discussão sobre } \\
\text { Envelhecimento Humano e os } \\
\text { Inquéritos da PNAD Saúde, } \\
\text { coordenado por Cadernos de } \\
\text { Saúde Pública, com estudos } \\
\text { sobre o padrão de acesso e } \\
\text { utilização dos serviços de saúde } \\
\text { pelos idosos, sobre o quadro } \\
\text { epidemiológico do câncer de } \\
\text { mama na população feminina da } \\
\text { terceira idade e sobre a validade } \\
\text { do uso de respondente substituto } \\
\text { na pesquisa sobre a } \\
\text { autoavaliação da saúde, } \\
\text { constatando-se } \\
\text { informações da PNAD são } \\
\text { consistentes e podem ser } \\
\text { utilizadas pela comunidade } \\
\text { científica. }\end{array}$ \\
\hline
\end{tabular}




\begin{tabular}{|c|c|c|c|}
\hline $\begin{array}{lr}\text { Percepções } & \text { de } \\
\text { profissionais } & \text { de } \\
\text { saúde sobre } & \text { duas } \\
\text { definições } & \text { de }\end{array}$ & $\begin{array}{l}\text { TEIXEIRA, I. } \\
\text { N. D. A. O. }\end{array}$ & $\begin{array}{l}\text { 2008/ } \\
\text { Brasil }\end{array}$ & 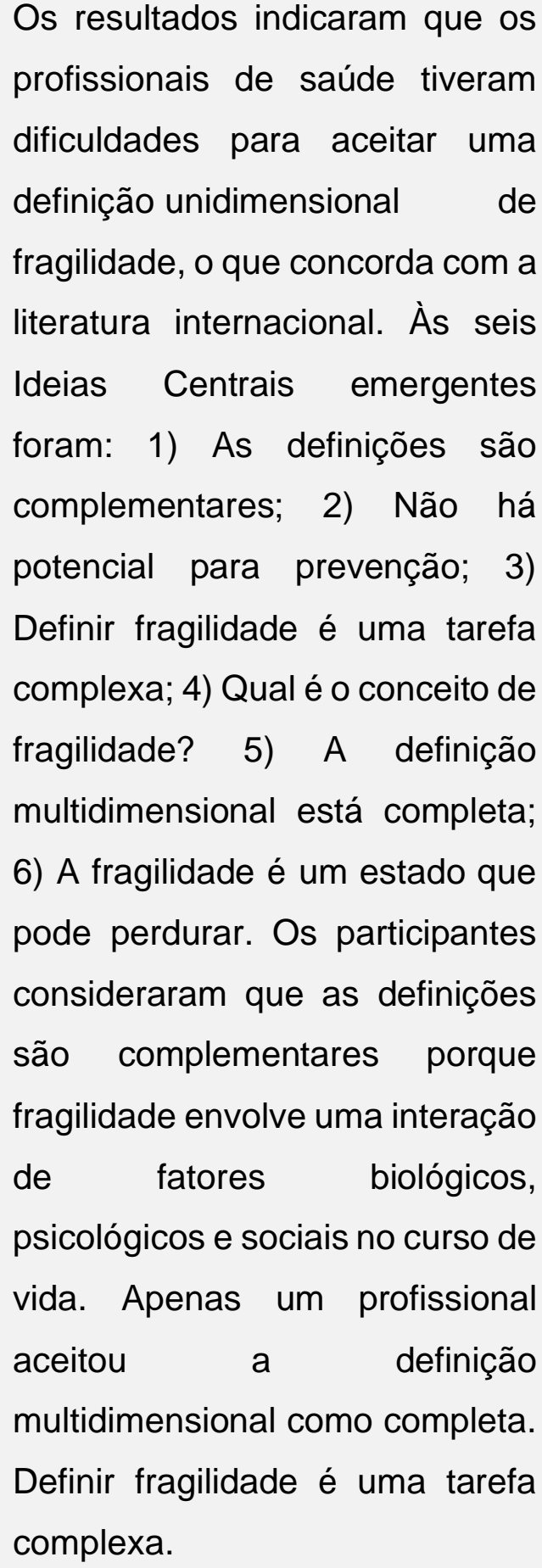 \\
\hline
\end{tabular}

Inclusão social de TORRES, M. 2008/ A implementação de muitas das idosos: um longo M.; SANTOS Brasil propostas de atenção ao idoso no caminho a percorrer SÁ, M. A. A..

Brasil envolve o exercício profissional do assistente social que, ao realizar ações de caráter 


\begin{tabular}{|c|c|c|c|}
\hline & & & $\begin{array}{l}\text { interventivo, favorece à } \\
\text { população idosa o acesso às } \\
\text { informações, à prestação de } \\
\text { serviço sócio assistencial, } \\
\text { fortalecendo sua condição de ser } \\
\text { cidadão. }\end{array}$ \\
\hline $\begin{array}{l}\text { Direitos Humanos, } \\
\text { envelhecimento } \\
\text { ativo e saúde da } \\
\text { pessoa idosa: marco } \\
\text { legal e institucional }\end{array}$ & $\begin{array}{l}\text { KEINERT, T. } \\
\text { M. M.; ROSA, } \\
\text { T. E. da C. }\end{array}$ & $\begin{array}{l}2009 / \\
\text { Brasil }\end{array}$ & $\begin{array}{l}\text { A Constituição Federal garante } \\
\text { aos idosos os direitos } \\
\text { fundamentais baseados na } \\
\text { dignidade da pessoa humana. } \\
\text { São Direitos Sociais, Políticos e } \\
\text { Civis posteriormente } \\
\text { regulamentados nas políticas } \\
\text { específicas aos idosos, às quais } \\
\text { devem ser implementadas, de } \\
\text { maneira geral, intersetorialmente. }\end{array}$ \\
\hline $\begin{array}{l}\text { Comparação } r \\
\text { qualidade de vida } \\
\text { entre idosos que } \\
\text { participam e idosos } \\
\text { que não participam } \\
\text { de grupos de } \\
\text { convivência na } \\
\text { cidade de ltabira-MG }\end{array}$ & $\begin{array}{l}\text { ALMEIDA, } \\
\text { A.; et al., }\end{array}$ & $\begin{array}{l}2011 / \\
\text { Brasil }\end{array}$ & $\begin{array}{l}\text { Os resultados sugerem que os } \\
\text { idosos que participam de grupos } \\
\text { de convivência apresentam } \\
\text { melhor qualidade de vida e menor } \\
\text { ocorrência de depressão quando } \\
\text { comparados a idosos que não } \\
\text { participam de grupos de terceira } \\
\text { idade. }\end{array}$ \\
\hline $\begin{array}{l}\text { Humanização na } \\
\text { Atenção à Saúde do } \\
\text { Idoso }\end{array}$ & LIMA, T. J. V & $\begin{array}{l}\text { 2010/ } \\
\text { Brasil }\end{array}$ & $\begin{array}{l}\text { Mostrou a existência de inúmeros } \\
\text { obstáculos impedindo que essas } \\
\text { políticas possam, de fato, ser } \\
\text { concretizadas, o que também } \\
\text { impede o cumprimento da } \\
\text { equidade, integralidade e }\end{array}$ \\
\hline
\end{tabular}




\begin{tabular}{|c|c|c|c|}
\hline & & & $\begin{array}{ll}\text { universalidade, } & \text { diretrizes } \\
\text { norteadoras do SUS. } & \end{array}$ \\
\hline $\begin{array}{l}\text { A contribuição do } \\
\text { trabalho do } \\
\text { assistente social em } \\
\text { centro de } \\
\text { convivência para } \\
\text { idosos: limites e } \\
\text { possibilidades }\end{array}$ & $\begin{array}{l}\text { MARTINS, L. } \\
\text { O. }\end{array}$ & $\begin{array}{l}2011 / \\
\text { Brasil }\end{array}$ & $\begin{array}{l}\text { Necessidade de um trabalho inter } \\
\text { e multidisciplinar, pois a velhice é } \\
\text { multifacetada, } \\
\text { contemporaneidade os vários } \\
\text { saberes específicos precisam } \\
\text { estar articulados para que haja } \\
\text { uma ampla discussão sobre esta } \\
\text { temática. Em especial, } \\
\text { profissional Assistente Social tem } \\
\text { o compromisso de estimular esta } \\
\text { discussão, principalmente com os } \\
\text { indivíduos que envelhecem, na } \\
\text { perspectiva de orientá-los a ter } \\
\text { um olhar crítico para a sua } \\
\text { realidade e fazê-los refletir sobre } \\
\text { os limites, as possibilidades e as } \\
\text { alternativas de vivenciar da } \\
\text { melhor forma o seu } \\
\text { envelhecimento. }\end{array}$ \\
\hline $\begin{array}{l}\text { Vulnerabilidade } \\
\text { social, individual e } \\
\text { programática em } \\
\text { idosos da } \\
\text { comunidade }\end{array}$ & $\begin{array}{l}\text { RODRIGUES, } \\
\text { N. O.; NERI, A. } \\
\text { L. }\end{array}$ & $\begin{array}{l}2012 / \\
\text { Brasil }\end{array}$ & $\begin{array}{l}\text { As variáveis que mais explicaram } \\
\text { a variação conjunta dos dados } \\
\text { pertencem ao domínio da } \\
\text { vulnerabilidade programática. A } \\
\text { renda associou-se com elas, } \\
\text { como era de se esperar. Essas } \\
\text { relações confirmam o raciocínio } \\
\text { expresso na hipótese norteadora } \\
\text { deste estudo. }\end{array}$ \\
\hline
\end{tabular}




\begin{tabular}{|c|c|c|c|}
\hline $\begin{array}{l}\text { Grupos de } \\
\text { convivência como } \\
\text { suporte ao idoso na } \\
\text { melhoria da saúde }\end{array}$ & $\begin{array}{l}\text { WICHMANN, } \\
\text { F. M. A.; et al., }\end{array}$ & $\begin{array}{l}\text { 2013/ } \\
\text { Brasil }\end{array}$ & $\begin{array}{l}\text { Pode-se observar que as } \\
\text { relações sociais e o suporte } \\
\text { social, sendo este emocional, } \\
\text { instrumental ou informacional, } \\
\text { favorecem a melhora da saúde. } \\
\text { As atividades mais comentadas e } \\
\text { realizadas pelos idosos, do Brasil } \\
\text { e da Espanha, são as } \\
\text { relacionadas à sociabilidade, } \\
\text { expressas no contato com os } \\
\text { amigos, ocasião em que buscam } \\
\text { compartilhar alegrias, tristezas e } \\
\text { conhecimentos. }\end{array}$ \\
\hline
\end{tabular}

Proteção social aos SILVA, M. do 2014/ A necessidade de planejamento e idosos: concepções, R. de F.; Brasil a adoção de medidas com diretrizes e YAZBEK, M. C amplitude de cobertura nas áreas reconhecimento de direitos na América Latina e no Brasil da educação, saúde, assistência social, segurança alimentar, habitação, trabalho e emprego, mobilidade e acessibilidade e que possam atender a urgência desse segmento social em buscar qualificar a trajetória de sua longevidade para esta e para as futuras gerações.

A importância de PINHEIRO, O. 2018/ A partir dos resultados Políticas Públicas D. dos S.; Brasil apresentados, é entendido o para idosos AREOSA, S. V. quanto se faz importante pensar C. as políticas públicas para essa população, de forma a garantir seus direitos em sociedade, pois 


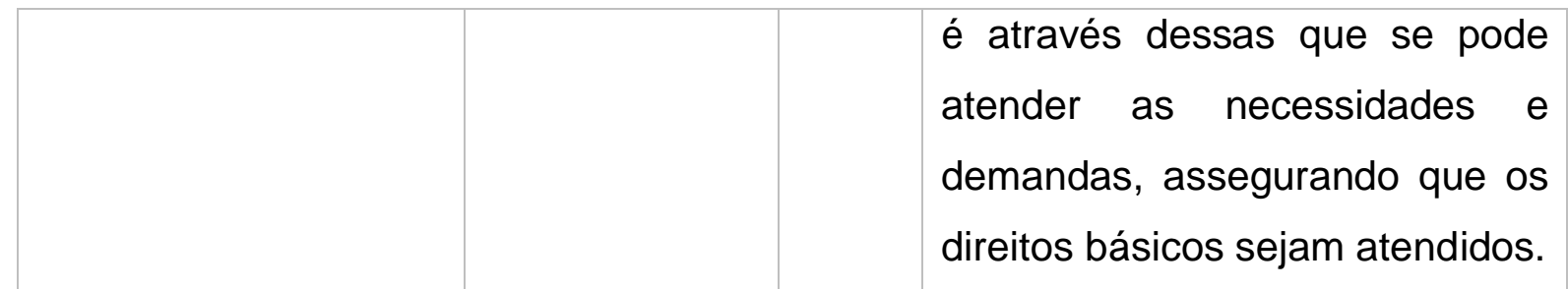

Fonte: Dados da Pesquisa, 2019.

\section{DISCUSSÕES}

O envelhecimento populacional constitui um fenômeno mundial e perspectiva local, que Lima (2010) atribui às modificações ocorridas de maneira acelerada e radical nas últimas décadas e que contribuíram significativamente para o declínio da fecundidade e da melhoria de vida da população. De acordo com dados do Censo Demográfico de 2010 a expectativa de vida do brasileiro soma 73,4 anos enquanto em 1980, esse número totalizava 62,57 anos; razão para as projeções mais conservadoras indicam que em 2030 seremos o quinto país do globo em número de idosos.

Para Veras (2007) o nosso país é configurado como um moço de cabelos brancos, explicado pela inclusão de mais 650 mil novos idosos todos os anos, estando os mesmos limitados funcionalmente ou portadores de doenças decorrentes da fisiologia do envelhecimento.

Diante dos dados acima expressos, o aumento expressivo da população idosa constitui hoje no Brasil uma vertente de pesquisa importante para gestores sociais e políticos em razão da necessidade desses atores urgentemente discutirem políticas e estratégias de atenção, tanto a população mais idosa como aqueles que estão em processo de envelhecimento, tanto na perspectiva de ampliar a taxa de sobrevida desses, como de evitar doenças ou sequelas decorrentes dos processos fisiológicos da velhice (VERAS, 2007).

Para Torres e Santos Sá (2008) o que se observa na atualidade é o envelhecimento analisado como uma das expressões do aumento da expectativa de vida e diminuição da taxa de natalidade, além da estigmatização construída sobre a figura idosa como 
um ser que não é mais capaz de produzir na sociedade capitalista. Perspectiva essa que vem acarretando sérios problemas nas relações que se estabelecem entre a família e o idoso e entre a sociedade e o idoso.

A exclusão social do idoso está intimamente ligado ao sistema econômico vigente na sociedade que exclui os que não produzem mais e esta tendência acaba por desencadear o desenvolvimento de vertentes entre os jovens de não admitir o envelhecimento, mas de pensar nesse processo como um momento de grande vulnerabilidade física, psicológica e social (TORRES; SANTOS SÁ, 2008).

Para Silva e Yazbek (2014), envelhecer e o ato de se tornar idoso são coisas totalmente distintas. Para as autoras, o processo de envelhecer começa desde o momento em que o indivíduo nasce e compreende todo o seu desenvolvimento físico, psicológico e social, enquanto o "tornar-se idoso" apresenta diferentes concepções.

A Organização Mundial de Saúde, o Estatuto do Idoso e a Política Nacional do Idoso defendem o ser idoso como o indivíduo que alcança a idade de 60 anos. Trata-se, portanto, de uma definição muito simples que desconsidera particularidades do processo de envelhecimento (LIMA, 2010).

Em meio às contradições e particularidades regionais existentes no Brasil, a idade em que a pessoa passa a ser idosa é comum a todo o território, afirmando o não compromisso com tais particularidades. Ao contrário disso, o que ocorre é que as pessoas envelhecem, mas não comumente e geral a todos os indivíduos, as experiências ao longo da vida diferem e a forma como tais interferem no modo de viver e pensar é particular a cada ser, a percepção da realidade, são distintos. Assim, não podemos fazer considerações generalistas e homogêneas sobre o processo de envelhecimento (LIMA, 2010).

Dessa forma, a percepção dos idosos sobre a sua velhice é variável segundo o grupo social/cultural a qual está inserido, bem como suas condições econômicas e fisiológicas de vida (RODRIGUES et al., 2011). 
A sociedade, muitas vezes, atrela o conceito de velhice a pessoas portadoras de fragilidades, de aparência enrugada, portadora de uma ou várias patologias (RODRIGUES et al., 2011). Decerto, existem indivíduos nessas condições, essas são características inerentes ao indivíduo, alguns com um pouco dessas características, outros com excesso; contudo, já dizia Texeira (2008), o envelhecimento não é sinônimo de doença, o ser humano é alguém suscetível às mais diversas categorias de patologias. A progressividade do viver enuncia a redução da capacidade do sistema imunológico em defender o organismo, mas não significa dizer que todo idoso adoeça ou contraia alguma patologia.

Silva e Yazbek (2014) conseguem visualizar a sociedade como a grande vilã para a velhice e justifica tal concepção afirmando que as mudanças efêmeras que surgem das transformações transcorridas no interior da sociedade de classe rompem as relações entre os homens e entre estes e a natureza, contribuindo para a dispersão da família.

As autoras fazem uma crítica quanto aos princípios morais que existem na sociedade contemporânea e às estratégias e ferramentas disponíveis para aplicação desses princípios. Ou seja, a sociedade que constrói leis e normas para o cuidado ao idoso é a mesma sociedade que discrimina a velhice, a redução da capacidade fisiológica desse ser e a mesma que, ao contrário de diminuir os obstáculos e percalços de grande importância para essa fase, faz com que o idoso se sinta excluído e impotente. A cultura da sociedade contemporânea valoriza a figura do jovem, como alguém que pode desenvolver-se intelectual e profissionalmente, enquanto espera que os anciãos abdiquem do trabalho e de outras atividades (SILVA; YAZBEK, 2014).

Wichmann et al., (2013) afirmam que a família nos moldes atuais não mais é concebida como um grupo que direciona suas atenções para o idoso, o que leva ao comprometimento emocional e, consequentemente, sofrimento e adoecimento. Para os autores Wichmann et al., (2013), Boff já relatava isso no ano de 1999, quando afirmou que $o$ indivíduo deve receber cuidados desde o nascimento até a sua morte e, caso isso não aconteça, ele debilita-se, perde sentido e morre. Para tanto, o autor defende que o cuidado deve ter grande empreendimento no que se propõe a fazer, 
pois, do contrário, prejudica a si próprio e a tudo o que está ao redor, ou seja, deve ser entendido na linha da essência humana e está presente em todas as circunstâncias.

Antes, ao pensar nas relações de trabalho, o trabalhador manual mais antigo era o que continha mais experiência, ou seja, os anos representavam sinônimo de "perfeição" e a destreza no ofício. Hoje, o trabalhador é visto como um mero reprodutor de gestos, executor de trabalho, um número a mais ou a menos de mão de obra. Resultado dessa mudança de concepção: quanto mais velho o trabalhador, maior a necessidade de "troca/substituição" dessa peça por uma mais "nova" e eficiente. Dessa forma, o mundo da pessoa idosa, no ambiente capitalista é mais fechado e restrito, uma vez que os valores dos indivíduos mais jovens são os que mais predominam (RODRIGUES; NERI, 2012).

Diante disso, as modificações transcorridas ao longo das mudanças da sociedade capitalista acabam por influenciar também o ambiente de convivência, o que determina a necessidade de apoio de políticas públicas voltadas para essa parcela significativa da população, para fortalecer os vínculos entre o idoso, família e sociedade, através do atendimento às necessidades desses três atores e do estudo de novas propostas e introdução de novos conceitos sobre a velhice, conceitos esses mais humanos (LIMA, 2010).

\subsection{PROTEÇÃO SOCIAL AO IDOSO}

A luta dos idosos por reconhecimento trouxe consigo um sentido novo, de ressignificação da velhice, na realidade como um tempo de poder adicionar qualidade melhor aos anos a existência humana (SILVA; YAZBEK, 2014). Neste aspecto, Keinert e Rosa (2009) reforçam que com o acréscimo da longevidade, trouxe a precisão de criação de políticas que habilitem os idosos a sua presença e lugar na sociedade.

Na década de 80 , os movimentos sociais de valorização e de respeito à pessoa idosa iniciaram um discurso mais ardente, contribuindo para a construção da Constituição 
de 1988, que instituiu a proteção e amparo jurídico a esse grupo. Contudo, a Constituição somente apontou os princípios acerca do tema, trazendo um tratamento programático, não mostrando políticas específicas para esta população (TORRES; SANTOS, 2008).

A Constituição de 1988 foi instituída e um dos seus fundamentos é a dignidade da pessoa humana, como fundamento para todos os direitos e as garantias individuais a serem respeitadas enquanto pessoa em relação à sua autonomia, liberdade, integridade física e moral e entre outros (BRASIL, 1988).

Como síntese das garantias constitucionais na área das políticas destinadas à população idosa, destaca-se: a Política Nacional do Idoso (PNI), promulgada em 1994 (Lei n. 8.842, de 04/01/1994), que traz no seu artigo primeiro como objetivo a necessidade de se "assegurar os direitos sociais do idoso, criando condições para prover a sua autonomia, integração e participação efetiva na sociedade", tendo a família, a sociedade e o Estado iguais responsabilidades na provisão de condições que permita a esse segmento social o exercício pleno de sua cidadania (KEINERT; ROSA, 2009; PINHEIRO; AREOSA, 2018).

Antes da promulgação da PNI, a lei Orgânica da Assistência Social (Loas) (Lei, n. 8.742, de 7/12/1993), já reconhecia a pessoa idosa como um dos seus segmentos de atenção prioritária. A Lei estabelece no artigo segundo, que a assistência social tem entre os seus objetivos: "a garantia de um benefício mensal de um salário-mínimo à pessoa portadora de deficiência e ao idoso que não possuir meios de prover a própria manutenção ou de tê-la provida por sua família", realidade concretizada com o Benefício de Prestação Continuada (BPC) (KEINERT; ROSA, 2009; SILVA; YAZBEK, 2014).

Como desdobramento da Lei Orgânica de Saúde (Lei n. 8.808/1990), que garantiu o direito universal e integral à saúde, em 1999 foi estabelecida a Política Nacional de Saúde do Idoso, regulamentada pela Portaria Ministerial (n. 1.395/1999) e regulamentada pela Portaria (n. 2.528/2006) que a renomeou como Política Nacional de Saúde da Pessoa Idosa, estabelecendo enquanto uma de suas diretrizes a 
promoção do envelhecimento saudável e ativo, segundo as recomendações da Organização das Nações Unidas - ONU. Outra importante cobertura foi concretizada com a concepção pelo governo do Estatuto do Idoso (Lei n. 10.741, 1/10/2003), com a finalidade de regular direitos assegurados às pessoas idosas com idade igual/superior a 60 (sessenta anos) (KEINERT; ROSA, 2009).

O Estatuto do idoso prevê no seu artigo segundo, que o idoso desfruta de todos os direitos fundamentais essenciais a pessoa humana, sem nenhum prejuízo da proteção integral, assegurando por meio da lei ou por outros meios todas as facilidades e oportunidades para a preservação de sua saúde física/mental e seu aperfeiçoamento intelectual, moral, social e espiritual em condições de dignidade e liberdade (KEINERT; ROSA, 2009; SILVA; YAZBEK, 2014). No artigo terceiro do Estatuto do Idoso relata ser obrigação da família, sociedade, comunidade e poder público assegurar com prioridade absoluta, "a efetivação do direito à vida, à saúde, à alimentação, à educação, à cultura, ao esporte, ao lazer, ao trabalho, à cidadania, à liberdade, à dignidade, ao respeito e à convivência familiar e comunitária" (BRASIL, 2009).

Fica claro a partir do exposto tanto na PNI como no Estatuto do idoso, que o reconhecimento da condição da pessoa idosa supõe a garantia de esforços que promovam a sua condição plena de cidadania, assegurando a sua autonomia, integração e efetiva participação na sociedade (RODRIGUES et al., 2007; SILVA; YAZBEK, 2014).

Esse movimento de ressignificação da velhice, coloca como exigência o redirecionamento dos órgãos públicos no sentido de procurar por um lado, fortalecer as oportunidades de discussão sobre a problemática do envelhecimento e por outro, incorporar medidas claras que visem o atendimento de suas necessidades (SILVA; YAZBEK, 2014).

A estrutura legal combinada pelas legislações (LOAS, PNI e Estatuto do Idoso) vem se somar com a Política Nacional de Assistência Social (PNAS) em 2004, onde diretrizes passaram a figurar na proteção social básica e na proteção social especial, 
destinadas aos segmentos sociais que são prioritários, entre eles os idosos. As ações por esses dois níveis de proteção passaram a ser reguladas pelo Sistema Único de Assistência Social (SUAS), com competências e atribuições definidas em cada ente federativo e de supervisão geral do Ministério do Desenvolvimento Social e Combate à Fome (MDS) (RODRIGUES et al., 2007; KEINERT; ROSA, 2009).

Apesar dos significativos avanços do texto constitucional em termos dos direitos, a concepção de seguridade social incorporada se coloca ainda aquém das vontades que mobilizaram os movimentos na década de 80 que pontuavam a universalidade como princípio e redistribuição de renda como critério de igualdade e superação da desigualdade (KEINERT; ROSA, 2009).

A conformação dessa agenda pública subentende o reconhecimento dos direitos à vida, a longevidade e a dignidade como direitos dos cidadãos e dever do Estado. Do lado do poder público nesta ótica de responsabilização é imprescindível a definição definir do papel do Estado enquanto lugar de equalização de oportunidades e como ator de assistências e serviços. Em termos de política como ação intermediária do Estado é fundamental no aspecto de enfrentamento a dois desafios: a defesa do lugar do Estado como serviço público preciso e estrategicamente equalizador de oportunidades e a defesa do controle democrático e popular sobre suas ações através da cidadania organizada (SILVA; YAZBEK, 2014; PINHEIRO; AREOSA, 2018).

\subsection{O PAPEL DO CENTRO DE CONVIVÊNCIA DO IDOSO}

Os Centros de Convivência existem na sociedade brasileira, desde meados da década de 1960, quando o Serviço Social do Comércio - SESC, incluiu uma visão de convívio social, implementou ações que tinham por objetivo promover o bem-estar na velhice. Nesse contexto, os Centros eram instituições que preconizavam a promoção do idoso com o intuito de "viver mais", através de ações que contemplassem a qualidade de vida destes (RODRIGUES et al., 2011).

Para Wichmann et al., (2013) a Política Nacional do Idoso, instituída em 1994 é uma grande defensora da criação de Centros de Convivência como uma das mais variadas 
modalidades de atendimento a essa faixa etária da população. Trata-se de uma iniciativa de baixo custo econômico e de grande eficiência na promoção da figura idosa através de inciativas coesas com as políticas públicas, de educação, de assistência social, de saúde, etc.

Deste modo, os centros são apropriados para promover a ressocialização de idosos, elevando a sua autoestima e incentivando-os na luta pela cidadania plena e pela autonomia no desenvolvimento das mais variadas atividades. Através desses, o idoso pode adquirir novas experiências, lembrando ser essencial o estabelecimento de uma metodologia de sensibilização, de aproximação e de adaptação a estas atividades (WICHMANN et al., 2013).

A Resolução n. ${ }^{\circ}$ 109, datada de 11 de novembro de 2009, do Conselho Nacional de Assistência Social (CNAS) define o Serviço de Convivência e Fortalecimento de Vínculos para Idosos como sendo parte do Serviço de Proteção Social Básica que focaliza na criação de ferramentas que contribuam diretamente para o processo saudável de envelhecimento, da autonomia e sociabilidades, no fortalecimento de vínculos familiares e convívio social, incluindo a prevenção de situações de riscos sociais (ALMEIDA et al., 2011).

Nesse contexto, a intervenção social realizada por estes Centros precisa estar fundamentada nas características, demandas e interesses dos idosos, considerando a vivência em grupo, as experimentações culturais/artísticas, esportivas e lazer, e a valorização das experiências de vida como maneiras privilegiadas de interação, expressão e proteção social. Para tanto, as vivências devem valorizar as experiências dos indivíduos dessa faixa etária, como também estimular e potencializar a autonomia do processo de escolha e decisão, além de desenvolver neles um sentimento de utilidade (ALMEIDA et al., 2011).

Além disso, a interação dos idosos com outro indivíduo da mesma faixa etária cria possibilidades de reduzir o isolamento na terceira idade e restituem o seu sentido de pertencer. Fazer parte de um grupo para esses indivíduos, nada mais é, do que uma conquista, uma maneira de resilir com o cotidiano dos afazeres do lar e obrigações 
com os filhos/netos; adquirindo conhecimentos e desfrutando de "liberdade". Ou seja, participar dos grupos de convivência significa ainda, sair do isolamento, conviver com indivíduos da mesma idade e procurar uma atividade com o objetivo de dar sentido para a vida (ALMEIDA et al., 2011; WICHMANN et al., 2013).

Wichmann et al., (2013, p. 25) colocam que:

A satisfação com a vida é uma das medidas do bem-estar psicológico, que reflete a avaliação pessoal do indivíduo sobre determinados domínios. As redes de relações são importantes fontes de suporte social e estão relacionadas ao senso de bem-estar. Do mesmo modo, o nível de satisfação dos idosos na convivência com outras pessoas pode aumentar de intensidade no decorrer da vida, melhorando a qualidade de vida. Nos grupos, surge a oportunidade de estabelecer novas amizades, ampliar os conhecimentos e afastar a solidão.

A vida de cada indivíduo ganha maior significado quando compartilhamos com outro, e esta é uma indispensável condição para o envelhecimento bem-sucedido. Para a população de maior idade, a relação com o grupo, possibilita ainda experimentar com outras pessoas a individualidade, identificando assim objetivos comuns (WICHMANN et al., 2013).

A participação nos grupos torna-se importante neste momento da vida, pois tende a contrabalançar as perdas, especialmente as do grupo familiar. Para os sujeitos que chegam a este momento da vida, aparecem novas necessidades, se fazendo necessário adaptações para que vivam com dignidade. Desta forma, o foco desses centros de convivência está voltado para as trocas de vivências e experiências, pois as possibilidades são múltiplas destes sujeitos se reconhecerem nas interrogações diversas que a partir deste convívio surgem, ou seja, as angústias, os conflitos, como também as descobertas e a própria percepção acerca das expectativas e das possibilidades que surgem segundo sua inserção nos grupos de convivência (ALMEIDA et al., 2011).

Os grupos de convivência, portanto, têm consistindo em uma alternativa em todo o Brasil. Inicialmente a população idosa buscam, nesses grupos, melhoria física/mental, por meio dos exercícios físicos. Posterior, as necessidades aumentam e as atividades 
de lazer, como viagens ganham espaço, além do desenvolvimento de outras ações, sempre promovendo atividades lúdicas e ocupacionais (ALMEIDA et al., 2011; WICHMANN et al., 2013).

De acordo com Almeida et al., (2011), os grupos estimulam o idoso a adquirir autonomia, melhorar autoestima, qualidade de vida e senso de humor, promovendo sua inclusão social, através das mais diversas atividades pelos profissionais desenvolvidos do centro. Estes fatores influenciam diretamente a continuidade desse grupo nos programas e nas mudanças que ocorrem em suas vidas.

No entanto, vale lembrar que esses centros de convivência não podem ser apenas lugares de lazer e de diversão, mas, um local que possua ações educativas, direcionadas ao desenvolvimento social e também pessoal dos participantes (RODRIGUES et al., 2011).

\subsection{O DESAFIO DA INCLUSÃO SOCIAL DO IDOSO}

A inclusão social está intimamente relacionada à questão da proteção e do emprego social pela população em nosso país ocupado. Vivemos numa sociedade, onde os direitos são identificados enquanto favor, tutela, um benefício e não prerrogativa para o estabelecimento de uma vida digna socialmente e de qualidade (RODRIGUES; NERI, 2012).

Logo, proteção social pode ser intuída como o conjunto de atos que visam previr riscos, restringir impactos que podem ocasionar malefícios à vida dos sujeitos $e$, consequentemente, à vida em sociedade. A exclusão social acontece quando determinado grupo ou parcela é de alguma forma excluída dos seus direitos, ou ainda, tem seu acesso negado pela ausência de informação. Ao contrário disso, o conceito de inclusão está atrelado ao sentido de fazer parte, de sentir-se pertencente como pessoa humana, única e singular, incluso em sua condição de vida e de humanidade (TORRES, 2008; PINHEIRO; AREOSA, 2018). 
Destarte, inclusão e a proteção social estão intrinsecamente relacionadas aos direitos sociais. Rodrigues e Neri (2012) afirmam que o governo deve se importar diante da proteção ao idoso.

A inclusão e a proteção social estão intrinsecamente relacionadas aos direitos sociais. O ser idoso precisa de espaço próprio, principalmente para alguém já teve tantas perdas - emocionais, fisiológicas, produtivas, etc.; e se sente ameaçado acerca do seu lugar. Esta precisa sentir-se acolhido e amado, mantendo um papel sociocultural de destaque para sentir-se útil (RODRIGUES; NERI, 2012).

Nessa perspectiva, o Brasil participa de um movimento de assistência ao idoso amplo, com a finalidade de substituir o modelo asilar gradativamente, considerado uma prisão/hospício, pelo modelo na atenção ao idoso. A política em discussão passa a dar valor o trabalho em equipes interdisciplinares e multiprofissionais, assim como a pluralidade dos conhecimentos. Vale ressaltar que já existe diversidade, complexidade das ações e dos serviços assistenciais, que passaram a dominar o campo profissional e acadêmico (TORRES; SANTOS SÁ, 2008; RODRIGUES; NERI, 2012).

No tocante, na população idosa são identificados dois marcos legais: a Constituição de 1988, que estabelece, nos artigos 229 e 230, a obrigação de incluir nas políticas as necessidades e direitos desta população; e o Estatuto do Idoso, que garante os direitos e o estabelecimento das redes de proteção e 0 atendimento direcionados aos idosos (TORRES; SANTOS SÀ, 2008, MARTINS, 2011).

A legislação fortalece a discussão e coloca nas políticas o debate sobre o lugar ocupado pelos idosos brasileiros. O primeiro ponto, parece fundamental apresentar a legislação específica: a Política Nacional do Idoso, Lei 8842/94; Política Nacional de Saúde do Idoso, Portaria 2528 de 19 de outubro de 2006; e o Estatuto do Idoso, Lei 10.741/ 2003 (VERAS, 20007).

Este conjunto de leis, reconhecem o lugar social, além de identificar o significado da condição de cidadania desse segmento populacional. Essa maneira de entender as 
condições de vida associa-se a um entendimento de cidadania; reconhecendo ser um processo de aprendizagem social no fundamento de formas de relação novas, contribuindo para formação e constituição de cidadãos como sujeitos sociais ativos (RODRIGUES; NERI, 2012).

Exercer os direitos não é uma discussão de idade, saúde mental, condição social, mas deve sobrevir em qualquer tempo da vida, exigindo dos sujeitos uma tomada de consciência acerca das suas vivências, de sua possibilidade de expressar necessidades de forma individual/coletiva (SILVA; YAZBEK, 2014).

Outra perspectiva merecedora de destaque se refere o pequeno retorno dado por meio das políticas sociais em conexão a inclusão dos idosos nos programas e também serviços que garantam a sua qualidade de vida. O Brasil é um país que nos últimos anos apresenta dificuldade em equacionar os problemas na área da proteção básica como: o acesso à saúde, educação, habitação. Na sociedade brasileira, atender as necessidades decorrentes de tratamento das doenças crônicas e degenerativas, da cobertura da seguridade social, é quase que impossível para quem não tem o acesso a um plano de saúde e previdenciário, o que se pode inferir que as condições de atenção à velhice, não são compatíveis e condizentes com o que preconiza a legislação em vigor (SILVA; YAZBEK, 2014; PINHEIRO; AREOSA, 2018).

É necessário, e requer até mesmo uma certa urgência, formas mais humanas e universalizantes para agilizar o acesso às informações importantes que dizem respeito ao idoso.

No tocante ao Estatuto do Idoso, segundo Torres (2008) os direitos por ele previstos que apontam para o fortalecimento da inclusão social do idoso são: direito à vida (viver com devida dignidade, com acesso aos bens/serviços socialmente produzidos); direito à informação (ter informação, trocar ideias, questionar, perguntar, compreender) no sentido de ter acesso à tecnologia, informática, senha bancária, as notícias, aos eletroeletrônicos, entre outras, bem como no sentido de tomar conhecimento de como laboram os serviços prestados por meio da política social, como labora a rede de atendimento social, a gestão pública, os conselhos, como o poder público aplica o 
dinheiro na área do envelhecimento; direito à vida familiar, à convivência social/comunitária (receber apoio e apoiar a família, preservar laços e vínculos familiares, trocar experiência; receber suporte emocional, social e psicológico); direito ao respeito (às limitações, às diferenças, a forma de entender o mundo); direito à preservação da autonomia (ter preservada a capacidade de realizar tarefas sozinho ou com auxílio, ter preservada a privacidade e a capacidade de realizar as atividades diárias); direito do acesso aos serviços que asseguram as condições de vida (ter acesso aos serviços de saúde, educação, moradia, lazer, entre outros); direito de participar, opinar e resolver sobre sua própria vida (conhecer e participar dos conselhos, de atividades recreativas e de convivência) (MARTINS, 2011; SILVA; YAZBEK, 2014).

A instituição do Estatuto do Idoso representa um avanço significativo na legislação, com o escopo de garantir o respeito aos idosos, como também a consolidação e ampliação dos seus direitos, com o propósito de ofertar-lhes cidadania de fato e de direito às pessoas com idade superior a 60 anos. A positivação desses direitos faz-se extremamente necessário para afirmar a igualdade de todos perante a lei e dirimir a discriminação que existe pelo idoso (MARTINS, 2011).

\section{CONSIDERAÇÕES FINAIS}

O Brasil, antes considerado um país jovem, hoje está em pleno processo de envelhecimento segundo dados do IBGE (2014), onde a expectativa de vida encontrase em torno de 80 anos e muito em breve a população de idosos será predominante. Como em outros momentos da vida, a velhice é cheia de desafios, de dificuldades e avanços, de ganhos e também perdas. É necessário ter fé no potencial dos idosos e na sua capacidade de administrar a sua própria vida.

Diante dessa conjuntura do envelhecimento, é necessidade um trabalho multidisciplinar, uma vez que a velhice é multifacetada, e na contemporaneidade os vários conhecimentos específicos necessitam estar articulados para que de fato haja uma ampla discussão sobre esta temática. Em especial, o compromisso de estimular este debate, especialmente com os indivíduos que envelhecem, na perspectiva de 
orientá-los a apresentar um olhar crítico sobre sua realidade e fazê-los pensar sobre os limites, as possibilidades e as alternativas de vivenciar da melhor forma o seu envelhecimento. Assumindo assim, um papel de protagonismo ao se apoderar de um conjunto de ações que faz diminuir as possibilidades de exclusão e marginalização social que essa parcela da sociedade enfrenta diariamente.

Essa exclusão social, muitas vezes ocorre dentro da sua própria família e não são raros os relatos de violência doméstica contra o idoso proveniente de filhos e netos. Nesse contexto da discriminação e de preconceitos com a pessoa mais velha, o profissional assume papel imprescindível na coordenação dos grupos da terceira idade, tentando no atual cenário, a ampliação da atuação do Serviço Social em espaços profissionais como os grupos de convivência de idosos.

Ainda que os direitos sejam estabelecidos por lei, os responsáveis pela sua garantia nem sempre são direcionados para sua efetivação. A inclusão social tem se encontrada paralela à questão do direito e também da proteção social. A discussão sobre os direitos da população idosa tem sido ampliada nos últimos anos, tendo sido implementadas várias ações, de modo a garantir o que está estabelecido na lei.

Diante do exposto, afirma-se que apesar do quadro de entre os idosos e a sociedade em geral, é inegável a importância dos Centros de Referência no processo de desinstitucionalização da "velhice".

\section{REFERÊNCIAS}

ALMEIDA, E. A.; et al. Comparação da qualidade de vida entre idosos que participam e idosos que não participam de grupos de convivência na cidade de Itabira-MG. Rev Bras Geriatr Gerontol, v. 13, n. 3, p. 435-44, 2011.

BARROSO; N. P.; BATISTA, K. G. S.; DIAS, S. A.; COSTA, M. L. da. Políticas Públicas e a Defesa dos Direitos da Pessoa Idosa. Anais CIEH, v. 2, n. 1, 2015.

BOTELHO, L. L. R.; CUNHA, C. C. A.; MACEDO, M. O método da revisão integrativa nos estudos organizacionais. Gestão e Sociedade, v. 5, n. 11, p. 121-136, 2011. 
BRASIL. Estatuto do Idoso. 2. ed. rev. Brasília: Editora do Ministério da Saúde, 2009.

BRASIL. Lei n. 8.842, de 04 de janeiro de 1994. Dispõe sobre a Política Nacional do Idoso, cria o Conselho Nacional do Ido e dá outras providências [Internet]. Brasília; 1994. Disponível em http://www.planalto.gov.br/ccivil_03/leis//8842.htm. Acesso em nov. 2019.

DENTZ, M. V.; SILVA, R. R. D. da. Estratégias de intervenção do serviço social nas políticas de escolarização: uma análise contemporânea. Educ. Pesqui., São Paulo, v. 43 , n. 3, p. 695-710, 2017.

KEINERT, T. M. M.; ROSA, T. E. da C. Direitos Humanos, envelhecimento ativo e saúde da pessoa idosa: marco legal e institucional. BIS, Bol. Inst. Saúde (Impr.), v. 47, n. 1, 2009.

LIMA, T. J. V. Humanização na Atenção à Saúde do Idoso. Saúde Soc. São Paulo, v. 19 , n. 4 , p. $866-877,2010$.

MARTINS, L. O. A contribuição do trabalho do assistente social em centro de convivência para idosos: limites e possibilidades. Revista UNIABEU Belford Roxo, v. 4, n. 8, 2011.

MENDES, K. D. S.; SILVEIRA, R. C. C. P.; GALVÃO, C. M. Revisão integrativa: método de pesquisa para a incorporação de evidências na saúde e na enfermagem. Texto Contexto Enferm., v. 17, n. 4, p. 758-764, 2008.

PESSÔA, E. M. Assistência social ao idoso enquanto direito de Proteção social em municípios do Rio Grande do Sul. Tese Doutorado (Serviço Social) - Faculdade de Serviço Social, PUCRS, Porto Alegre, 2010.

PINHEIRO, O. D. dos S.; AREOSA, S. V. C. A importância de Políticas Públicas para idosos. Baru Goiânia, v. 4, n. 2, p. 183-193, 2018. 
RODRIGUES, N. O.; NERI, A. L. Vulnerabilidade social, individual e programática em idosos da comunidade: dados do estudo FIBRA, Campinas, SP, Brasil. Ciência \& Saúde Coletiva, v. 17, n. 8, p. 2129-2139, 2012.

RODRIGUES, R. A. P.; et al. Política nacional de atenção ao idoso e a contribuição da enfermagem. Texto Contexto Enferm. Florianópolis, v. 16, n. 3, p. 536-545, 2007.

ROSA, A. L. C. de S. O envelhecimento na pós-modernidade. In: LEMOS, M. T. T. B; ZABAGLIA, Rosângela A. A arte de envelhecer: saúde, trabalho, afetividade e estatuto do idoso. São Paulo: Idéias \& Letras, 2012.

SANTOS, F. H. dos; ANDRADE, V. M.; BUENO, O. F. A. Envelhecimento: um processo multifatorial. Psicol. estud. [online], v. 14, n. 1, p. 3-10, 2009.

SILVA, M. do R. de F.; YAZBEK, M. C. Proteção social aos idosos: concepções, diretrizes e reconhecimento de direitos na América Latina e no Brasil. R. Katál. Florianópolis, v. 17, n. 1, p. 102-110, 2014.

TEIXEIRA, I. N. D. A. O. Percepções de profissionais de saúde sobre duas definições de fragilidade no idoso. Cienc. Saúde Coletiva. v. 13, n. 4, p. 1181-1188, 2008.

TORRES, M. M.; SANTOS SÁ, M. A. A. Inclusão social de idosos: um longo caminho a percorrer. Revista Ciências Humanas. Universidade de Taubaté (UNITAU), v. 1, n. $2,2008$.

VERAS, R. Fórum Envelhecimento populacional e as informações de saúde do PNAD: demandas e desafios contemporâneos. Cadernos de Saúde Pública, Rio de Janeiro, v. 23, n. 10, p. 2463-2466, 2007.

WHITEMORE, R.; KNAFL, K. The integrative review: updated methodology. Journal of Advanced Nursing, v. 52, n. 5, p. 546-553, 2005.

WICHMANN, F. M. A.; et al. Grupos de convivência como suporte ao idoso na melhoria da saúde. Rev. Bras. Geriatr. Gerontol, Rio de Janeiro, v. 16, n. 4, p. 821-832, 2013. 
Enviado: Outubro, 2020.

Aprovado: Janeiro, 2021. 